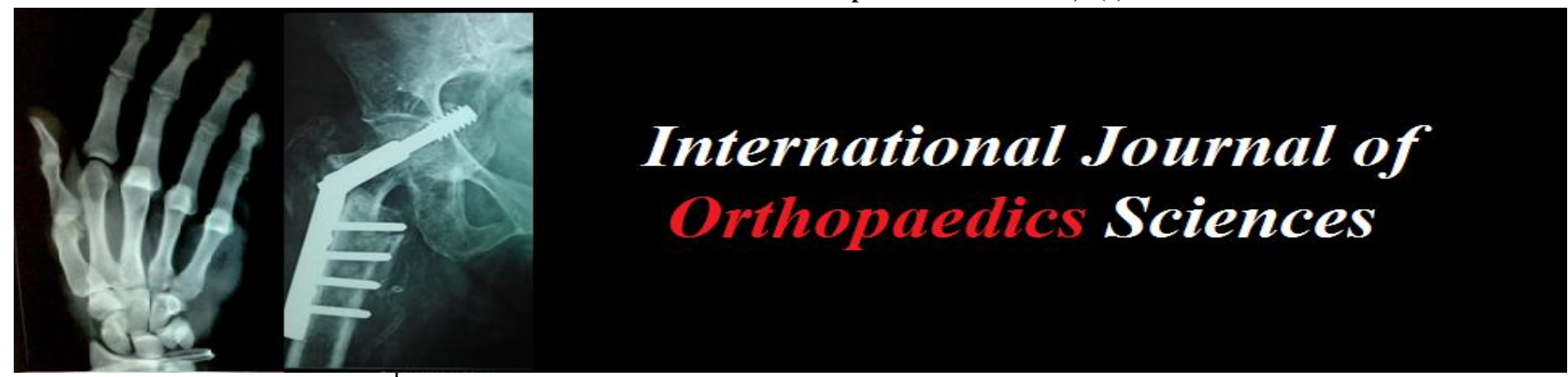

ISSN: $2395-1958$

IJOS 2018; 4(2): 48-50

(C) 2018 IJOS

www.orthopaper.com

Received: 12-02-2018

Accepted: 15-03-2018

Dr. K Satya Kumar

Ms Ortho Professor of

Orthopaedics, Nri Academy of

Sciences, Andhra Pradesh, India

Dr Riyaz Babu Shaik

Ms Ortho, Associate Professor of

Orthopaedics, Nri Academy of

Sciences, Andhra Pradesh, India

Dr Lakshmi Narayana Paladugu Junior Resident of Orthopaedics, Nri Academy Of Sciences,

Andhra Pradesh, India

Dr. Amarnath Surat

Ms Ortho Professor and Hod of Orthopaedics, Nri Academy Of

Sciences, Andhra Pradesh, India

Correspondence

Dr. K Satya Kumar

Ms Ortho Professor of

Orthopaedics, Nri Academy of

Sciences, Andhra Pradesh, India

\section{Role of double vs triple shot intra articular platelet rich plasma in early osteoarthrosis of knee}

\author{
Dr. K Satya Kumar, Dr. Riyaz Babu Shaik, Dr. Lakshmi Narayana \\ Paladugu and Dr. Amarnath Surat
}

DOI: https://doi.org/10.22271/ortho.2018.v4.i2a.09

\section{Abstract}

To Compare The Functional Outcome Of Patients With Osteoarthrosis Of Knee (KL Grade 2), Receiving Intra-Articular Injections Of Platelet Rich Plasma. A Prospective Study Of 120 Patients (Aged Above 30 Years) With Clinical And Radiological Diagnosis Of Osteoarthrosis Of Knee Joint (Unilateral/ Bilateral) Was Conducted During The Period Between January2016 To November 2017 In The Department Of Orthopaedics, Nri Academy Of Sciences, Chinakakani, Guntur (Dt), Andhra pradesh. Patients with Primary OA of Knee Were Divided Into Two Groups of 60 Each. One Group Was Administered IntraArticular two Injections Of PRP with post procedural oral analgesics for one week And The Other Group Was Administered Intra-Articular Three Injections Of PRP with topical analgesia without oral analgesics. Results Were Analysed Using IKDC, WOMAC, and VAS Criteria. Intra Articular PRP Is An Innovating Minimally Invasive Technique With A Low Procedure Cost. In Our Study We Conclude In Grade 2 Early Osteoarthritis Of Knee Three Shots Of Intra Articular Platelet Rich Plasma without the need for post procedural oral analgesics has given excellent results and it confirmed that three shots of prp has a significant role in getting pain relieved compared to two shots.

Keywords: role of double, shot intra articular, osteoarthrosis of knee

\section{Introduction}

Osteoarthrosis of knee is one of the most common musculoskeletal disability in the recent era. Its occurrence is $12.1 \%$ in population from 25 to 74 years old. Clinically it is heterogeneous and the process of deterioration until today is not clearly understood. A variety of agents, such as no steroidal anti-inflammatory drugs, glucosamine, chondroitin-sulphate, hyaluronic acid, and glucocorticoids have been used. But due to their limitations in the success rate various biological and regenerative methods are coming in to light. Current research highlights the potential use of specific growth factors as therapeutic proteins for cartilage repair, and have been widely investigated in vitro and in vivo.6, one amongst them is platelet rich plasma (PRP). Autologous platelet-rich plasma (PRP), contains a pool of growth factors, which offers an easy solution for delivering multiple growth factors needed for tissue repair. 4 PRP is being widely used in almost all areas of medicine today. Lack of clarity about the number and frequency of injections for grade 1 early osteoarthritis and grade 2 early osteoarthtis for appropriate effectiveness. Keeping in view these gray areas in our knowledge, this prospective clinical trial was designed to evaluate the role of double Vs triple shots intraarticular PRP in the early stages of knee OA [KL Grade 1 and Grade 2].

\section{Aim}

To compare the clinical and Functional Outcome of KL Grade 2 osteoarthrosis of knee receiving intrarticular injections of autologous platelet rich plasma.

\section{Objective}

To compare the Functional Outcomes between the two groups of patients, One group receiving two shots of prp with short term oral analgesics and another group receiving three shots of Intra-articular Platelet Rich Plasma, topical analgesic without oral analgesics us WOMAC,IKDC and VAS Scales. 


\section{Materials and Methods Study design}

It was a prospective study in which 120 patients were participated who are included into two groups $A(n=60) \&$ $\mathrm{B}(\mathrm{n}=60$.both the groups have KL grade 2 osteoarthritis cases.since the number of cases were more than 100, we decided to make them into 2 groups for ease of study \& analysis. cases were selected randomly into these 2 groups. we did select unilateral \& bilateral involved cases. Group A is again sub divided into group $A_{1}(n=30)$ \& group $A_{2}(n=30)$ and patients were included into sub groups $A_{1} \& A_{2}$. One sub group $\left(A_{1}\right)$ receiving two shots intar artticular PRP and Post procedural oral analgesics for 1 week another sub group $\left(A_{2}\right)$ receiving three shots of intraarticular PRP with topical analgesia within a span of $1 \&$ half months period,without post procedural oral analgesics. Group $\mathrm{B}$ is again sub divided into group $B_{1}(n=30)$ \& group $B_{2}(n=30)$ and patients were included into sub groups $\mathrm{B}_{1} \& \mathrm{~B}_{2}$ One sub group $\left(\mathrm{B}_{1}\right)$ receiving two shots intar artticular PRP and Post procedural oral analgesics for 1 week and another sub group $\left(B_{2}\right)$ receiving three shots of intraarticular PRP, with topical analgesics within a span of $1 \&$ half month period without post procedural oral analgesics. Each patient were followed post procedure at 6 weeks, 3 months, and 6 months.

After taking institutional ethics committee clearance, informed consent of voluntary patients Demographic Data, Brief medical history were be taken, along with Clinical Examination and Routine Investigations (i.e. Complete Blood Count, Serology, Bleeding and Clotting Time, RA factor, ASLO, CRP, ESR, Serum Uric Acid Levels) were done for all the patients enrolled in the study.

- Radiological Investigation and OA StagingAnteroposterior and Lateral

Radiographs of Both Knees in standing position (Stress view) was done for all

Patients. Based on Kellegren-Lawrence system of grading, the radiological staging of OA was done for each patient. Patients with KL Grades 3 \& 4 were excluded from the study

- Documentation of Baseline Functional Outcome of the affected knee/ knees was

Done using patient satisfaction levels by questionnaire, visual analogue (VAS) scale. Then the patients were divided into two groups, i. e A \& B randomly. Group A is subdivided into group A1 (KL grade 2a) and group A2 (KL grade 2b), Group $\mathrm{B}$ is subdivided into group B1 (KL grade 2a) and group B2 (KL grade 2b). PRP was prepared from whole blood by 'Double spinning differential centrifugation 'method.

\section{Steps for Preperation}

1. $34 \mathrm{ml}$ of venous blood is drawn into a syringe containing $6 \mathrm{ml}$ of ACD (acid citrate dextrose) to finally get $4-5 \mathrm{ml}$ of platelet rich plasma.

2. It is centrifused ( $\left(1^{\text {st }}\right)$ for 15 minutes with a setting of 1500 rpm along with counter balance to the syringe.

3. Three layers were formed upper being the platelets containing plasma, middle being the buffy coat layer, lower being the RBC.

4. Upper layer was drawn out into another syringe.

5. it is centrifused $\left(2^{\text {nd }}\right)$ for 7-8 minutes with a setting of $3500 \mathrm{rpm}$ which is very rapid, essential for platelets to sediment along with the counter balance.

6. Platelets were sedemented much down with platelet poor plasma being on the top.

7. Platelet poor plasma was withdrawn out with $4-5 \mathrm{ml}$ left in the syringe which was shaken to mix up the platelet sediment.

8. Additional $34 \mathrm{ml}$ of venous blood was taken in another syringe with $6 \mathrm{ml}$ of ACD and this syringe is used throughout The procedure in place of counter balance for bilateral knee injection.

PRP prepared was injected into the knee after a thorough aseptic preparation of the knee in the operating room, via lateral joint space entry into the knee which was of my choice.
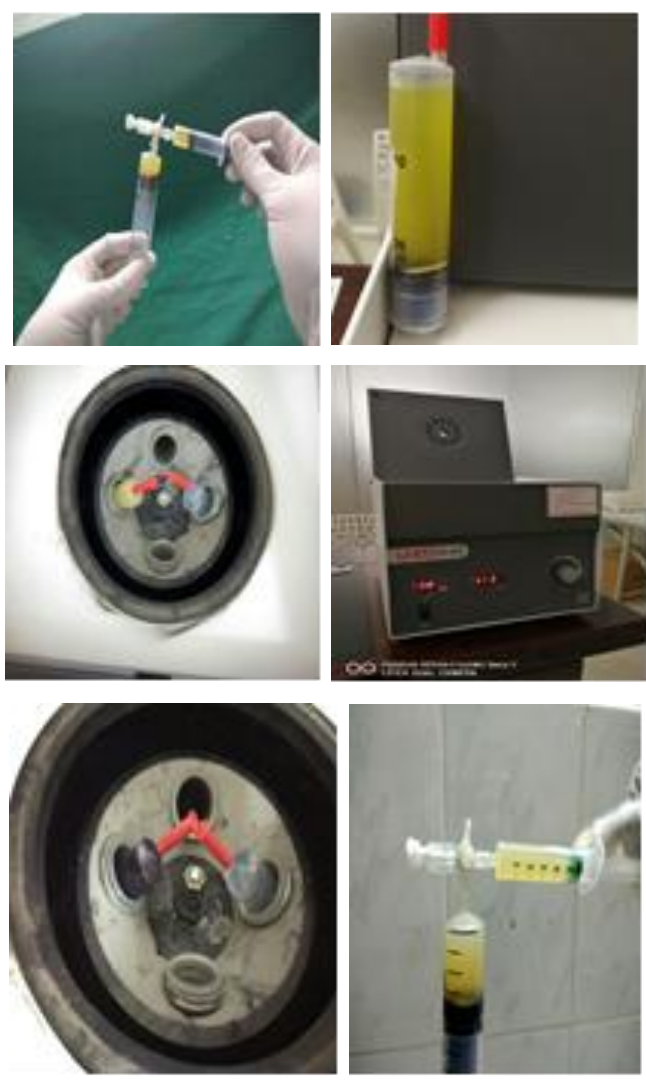

Group A was given with two shots of intra articular PRP and group B was given with three shots of intra articular PRP with a gap of two weeks period for each shot.

\section{Post procedural Care}

Patient Vitals were monitored for 30mins after infiltration, to observe for any sudden drop in BP, tachycardia, allergic reactions etc. Patients were advised Cold pack compressesion to alleviate immediate post-procedural pain. Patients were allowed to go

Home on the same day with full weight bearing ambulation advice.

\section{Results}

Table 1: Results were analysed by patient questionnaire and VAS pain scale grading

\begin{tabular}{|c|c|c|}
\hline Age & No of patients & Percentage (\%) \\
\hline $30-40$ & 24 & $20.0 \%$ \\
\hline $40-50$ & 62 & $51.6 \%$ \\
\hline $50-60$ & 34 & $28.3 \%$ \\
\hline
\end{tabular}

Table 2: sex distribution:

\begin{tabular}{|c|c|c|}
\hline Sex & No of patients & Percentage (\%) \\
\hline Male & 45 & $37.5 \%$ \\
\hline Femae & 75 & $62.5 \%$ \\
\hline
\end{tabular}


Table 3: Patient Questionnaire for Clinical and Functional Satisifaction

\begin{tabular}{|c|c|c|c|}
\hline Sub group & Average & Good & Excellent \\
\hline $\mathrm{A}_{1}(\mathrm{n}=30)$ & - & $08(26.6 \%)$ & $22(73.3 \%)$ \\
\hline $\mathrm{A}_{2}(\mathrm{n}=30)$ & - & $06(20 \%)$ & $24(80 \%)$ \\
\hline $\mathrm{B}_{1}(\mathrm{n}=30)$ & & $14(46.6 \%)$ & $16(53.3 \%)$ \\
\hline $\mathrm{B}_{2}(\mathrm{n}=30)$ & - & $5(16.6 \%)$ & $25(83.3 \%)$ \\
\hline
\end{tabular}

\section{Discussion}

Platelets are fragments of megakaryocytes in the cytoplasm, formed in the marrow_and nearly $2 \mu \mathrm{m}$ in diameter. They contain more than 30 bioactive proteins, most of which have a fundamental role hemostasis or tissue healing.

Seven basic protein growth factors that are actively secreted by platelets initiate all wound healing process. PRP also includes three proteins in blood known to work/act as cell adhesion molecules: Fibrin, fibronectin and vitronectin.

Activation induces the granules present in platelets to fuse to its cell membrane (also called degranulation) where the secretory proteins (e.g. PDGF, TGF- $\beta$ etc.) are transformed to a bioactive state by the addition of histones and carbohydrate side chains. The active proteins are then secreted, binding to transmembrane receptors of target cells, which are mesenchymal stem cells, osteoblasts, fibroblasts, endothelial cells and epidermal cells. These agonists bound transmembrane receptors and then activate an intracellular signal protein that causes the expression of a gene sequence that directs cellular proliferation, matrix formation, osteoid production, collagen synthesis etc. thus provoking tissue repair and tissue regeneration.

The active secretion of these growth factors by platelets begins within 10 minutes after activation, with more than $95 \%$ of the pre-synthesized growth factors secreted within 1 hour. Marx proposed that platelet in count of $10 \mathrm{lakh} / \mathrm{ml}$ in $5 \mathrm{~mL}$ of PRP, as a working definition of PRP, based on the scientific proof of bone and soft tissue healing enhancement.

\section{Summary}

This is a prospective study in which 120 patients involved. all 120 were of kellegren Lawrence grade 2.

45 of them are male and 75 of them are females. Total 135 knees are involved. Half the patients are given two shots of intra articular injection of PRP along with post procedural oral analgesics for 1 week and another half are given three shots of intra articular injection of PRP, with topical analgesia without oral analgesics. Results were analysed using pre and post procedure VAS pain scale grading and patient questionarrie.

\section{Conclusion}

As already known platelet rich plasma induces tissue healing and has well regeneration capacity which is the main basis for its usage in osteoarthritis. I conclude in my study that for KLGRADE2 (A1\&B1)early osteoarthrosis of knee two shots of intra articular injection of platelet rich plasma with little use of analgesics is enough to show short term good results to relieve pain with very less number of patients having need for third shot of PRP injection and for KLGRADE2(A2\&B2)early osteoarthrosis of knee with three shots of intra articular PRP injection, with topical analgesia without oral analgesics showed excellent long term results. This study helped us in selecting number of PRP's to be used in KL grade 2 OA. Group received 3 shots of PRP showed excellent long term results even without use of oral analgesics. Its efficacy in more than 2 years follow up to be studied further.

\section{References}

1. Buckwalter JA, Mankin HJ. Articular cartilage: degeneration and osteoarthrosis, repair, regeneration, and transplantation. J Bone Joint Surg Am. 1997; 79A (4):612-632.

2. Gobbi A. New possibilities for cartilage repair. Eur Musculoskelet Rev. 2010; 5(2):64-68.

3. Buckwalter JA, Brown TD. Joint injury, repair, and remodeling: roles in post-traumatic osteoarthritis. Clin Orthop Relat Res. 2004; 423:7-16.

4. Tran-Khanh N, Hoemann CD, McKee MD, Henderson JE, Buschmann MD. Aged bovine chondrocytes display a diminished capacity to produce a collagen-rich, mechanically functional cartilage extracellular matrix. J Orthop Res. 2005; 23:1354-1362.

5. Pietrzak WS, Eppley BL. Platelet rich plasma: biology and new technology. J Craniofac Surg. 2007; 16(6):10431054.

6. Frisbie DD, Kawcak CE, Werpy NM, Park RD, McIlwraith CW. Clinical, biochemical, and histologic effects of intra-articular administration of autologous conditioned serum in horses with experimentally induced osteoarthritis. Am J Vet Res. 2007; 68:290-296. 